\title{
Sosialisasi dan Pengenalan Computational Thinking kepada Guru pada Program Gerakan Pandai oleh Bebras Biro Universitas Bumigora
}

\author{
Kartarina ${ }^{1}$, Miftahul Madani ${ }^{2}$, Diah Supatmiwati ${ }^{3}$, Regina Aprilia Riberu ${ }^{4}$, Indah Puji \\ Lestari $^{5}$ \\ kartarina@universitasbumigora.ac.id ${ }^{1}$, madani@universitasbumigora.ac.id², \\ diah.supatmiwati@universitasbumigora.ac.id ${ }^{3}$, reginaaprilia2000@gmail.com ${ }^{4}$, \\ lestariindahpuji6@gmail.com ${ }^{5}$ \\ 1,2,3,4,5 Universitas Bumigora
}

\section{Article History:}

Received: 14-06-2021

Revised: 02-07-2021

Accepted: 07-07-2021
Keywords:

Computational Thinking, Bebras, Indonesia Komputasi

\begin{abstract}
Currently school teachers, especially in Mataram City, West Lombok Regency, Central Lombok and East Lombok are not familiar with learning with the concept of computational thinking (Computational Thinking) so they cannot teach their students how to think computationally as an approach to solving existing problems. Considering one of the demands of the industrial revolution 4.0, where problem solving skills are one of the abilities that students must have. In this case, these abilities need to be taught by teachers at school. Therefore, this problem must be solved immediately by increasing the ability of teachers in learning computational thinking so that teachers can apply computational thinking learning methods to their students. From the problems listed, it is necessary to approach how to train teachers to teach computationally thinking to their students. In Lombok, West Nusa Tenggara, to apply Computational Thinking (CT) in formulating problems and revealing solutions, namely through socialization and training and mentoring of free computational thinking materials to teachers in schools in Lombok, NTB which was held in the form of CT Bebras socialization activities, which is expected to help introduce and apply Computational Thinking (CT) material as a creative learning method in schools in NTB.
\end{abstract}

\section{Pendahuluan}

Salah satu kemampuan yang dibutuhkan seseorang untuk menghadapi revolusi industri 4.0 adalah melalui berpikir komputasi (Computational Thinking). Hal ini berdasarkan pendapat Wing yang menyatakan bahwa berpikir komputasi telah menjadi kemampuan dasar yang harus dimiliki setiap orang di abad ke dua puluh satu saat ini seperti halnya membaca, menulis, dan berhitung. Pendapat serupa juga disampaikan oleh National Research Council (NSF) dalam yang menyatakan bahwa berpikir komputasi merupakan kebutuhan setiap individu, bukan hanya bagi programmer. Karena kemampuan berpikir komputasi membantu individu dalam mengelola informasi secara efektif dan efisien dengan menggunakan teknologi terutama dalam era digital seperti sekarang ini. 
Pentingnya berpikir secara komputasi atau bisa disebut dengan Computational Thinking (CT) kepada guru dan siswa usia sekolah baik SD, SMP dan SMA, maka perlunya pengenalan dan penerapan materi Computational Thinking sebagai solusi problem solving. Anak-anak usia sekolah dapat memecahkan masalah setelah melatih diri dengan pengenalan materi CT Bebras.

Bebras adalah sebuah inisiatif internasional yang bertujuan untuk mempromosikan computational thinking di kalangan guru dan murid serta untuk masyarakat luas. Computational thinking adalah proses berfikir penyelesaian masalah dengan menggunakan teknik ilmu komputer (informatika).

Saat ini guru-guru sekolah khususnya di Kota Mataram, Kabupaten Lombok Barat, Lombok Tengah dan Lombok Timur belum mengenal pembelajaran dengan konsep Berfijkir komputasi (Computational Thinking) sehingga belum bisa mengajarkan kepada siswanya cara berpikir komputasi sebagai pendekatan untuk menyelesaikan persoalan yang ada. Mengingat salah satu tuntutan revolusi industri 4.0, dimana kemampuan pemecahan masalah merupakan salah satu kemampuan yang harus dimiliki siswa. Dalam hal ini kemampuan tersebut perlu diajarkan oleh guru pada bangku sekolah. Oleh karena itu permasalahan ini harus segera diselesaikan dengan meningkatkan kemampuan guru dalam pembelajaran computational thinking sehingga guru dapat menerapkan metode pembelajaran berpikir secara komputasi kepada siswa-siswinya.

Salah satu upaya Bebras Biro Universitas Bumigora (Bebras UBG) dalam memperkenalkan Computational Thinking adalah melalui kegiatan Roadshow untuk mensosialisasikn CT melalui "Gerakan PANDAl", kegiatan roadshow diawali dengan mengunjungi beberapa wilayah di lombok salah satunya di Pondok Belajar Fikri Cendikia Insani. Kelompok belajar tersebut merupakan salah satu kelompok belajar yang bertujuan untuk memberdayakan atau meningkatkan semangat belajar bagi anak-anak di sekitar desa Jenggala. Kelompok belajar ini mengajarkan banyak hal dalam soal pendidikan bagi anakanak yang tinggal di sekitar pondok belajar, di pondok ini terkadang di ssediakan wifi gratis supaya anak-anak sekitar mau datang untuk belajar.

Selain itu Bebras UBG juga mensosialisaskan CT ke sekolah-sekolah dan madrasah-madrasah di sekitar kota mataram, lombok barat dan lombok tengah dan lombok timur, hal ini dilakukan karena dengan cara mengumpulkan guru-guru untuk mengikuti sosialisasi CT diharapkan guru-guru bisa lanjut ke workshop dan pelatihan yang akan diberikan oleh Bebras Biro UBG.

Dari permasalahan yang tertera perlu adanya pendekatan bagaimana melatih guru untuk mengajar konsep CT atau berfikit secara komputasi kepada guru. Di Lombok, Nusa 
Tenggara Barat untuk menerapkan Computational Thinking (CT) dalam merumuskan masalah dan mengungkapkan solusinya yaitu melalui sosialisasi dan pelatihan serta pendampingan materi CT kepada guru di sekolah-sekolah di Lombok, NTB yang diselenggarakan dalam bentuk kegiatan sosialisasi CT Bebras, yang diharapkan dapat membantu mengenalkan dan menerapkan materi CT sebagai metode pembelajaran kreatif pada sekolah - sekolah di NTB.

\section{Metode}

1. Metode Pendekatan

Metode pendekatan yang dilakukan dalam memperkenalkan CT diawali dengan pengiriman surat ke sekolah-sekolah yang ada di Kota Mataram, Lombok Barat, Lombok Tengah, dan Lombok Timur dimana didalam surat tersebut bertujuan untuk diberikannya kesempatan memperkenalkan Computational Thinking (CT) dan Bebras kepada guru. Setelah surat yang dikirmkan tersebut ditanggapi oleh sekolah yang kemudian melaksanakan roadshow pengenalan CT dan Bebras pada program Gerakan PANDAI ke sekolah-sekolah dalam rangka pengenalan atau sosialisasi CT Bebras.

2. Metode Pelaksanaan

\section{A. Tahap Pertama}

[1] Sebelum kegiatan guru akan diberi pengarahan untuk membuka Google Classroom dan membuka link situs-situs terkait CT, seperti CTFirst, Google Computational Thinking, csunplugged.

[2] Tim dosen pembina dan mahasiswa (pelaksana pengabdian kepada masyarakat) mengenalkan progrm Gerakan PANDAI kepada guru-guru yang hadir.

[3] Pembuatan akun bebras latihan CT pada Bebras kepada guru secara unplugged (Memakai Kartu Bebras).

[4] Mengenalkan lomba Bebras bagi Siswa, akun pendaftaran beserta dengan alamat URL Bebras.or.id kepada guru madrasah.

B. Tahap Kedua

[1] Mengenalkan soal-soal dan pembahaan CT pada website Bebras.or.id

[2] Melatih guru untuk memilah-milah soal mana yang dapat dijadikan contoh untuk bahan ajar misalnya pada mata pelajaran (opsional, matematika, IPA, IPS, Bahasa Indonesia)

[3] Sosialisasi kepada guru-guru madrasah bagaimana mengemas CT kedalam mata pelajaran yang di ampu.

[4] Mengenalkan Soal CT bermuatan High Order Thinking Services (HOTS) 
[5] Mengajak guru untuk buat akun lomba bebras dan meminta guru untuk Mengikut sertakan siswanya untuk mengkuti lomba bebras.

\section{Pembahasan}

1. Target

Target dari pelaksanaan Roadshow sosialisasi ini adalah:

a. Guru-guru yang telah dikenalkan CT, Bebras dan Gerakan PANDAI memperoleh pengetahuan dasar tentang CT, Bebras dan Informatika yang diinjeksikan pada mata pelajaran opsional seperti pada Informatika, Matematika, pada IPA, IPS atau Bahasa.

b. Adanya MoU dari pimpinan sekolah / madrasah untuk menelegasikan guru-guru mata pelajaran IPA, IPS, Matematika, Bahasa dan Informatika untuk di daftarkan pada program Gerakan PANDAI di biro UBG.

c. Terdapat minimal 480 guru tingkat SD/MI dan SMP/MTs di sekitaran Lombok Nusa Tenggara Barat (NTB) yang mengikuti Pelatihan CT pada program kegiatan Gerakan Pandai yang dilatih oleh dosen pembina bebras biro UBG.

d. Adanya Guru yang mengajak siswa/ siswinya untuk berlatih Bebras CT untuk mengikuti lomba Bebras (Bebras Challenge 2020).

e. Adanya siswa / siswi yang mengikuti Lomba Bebras yang dilakukan setiap tahun secara online melalui komputer, yang dilombakan dalam lomba adalah sekumpulan soal yang disebut Bebras task.

2. Luaran

a. MoU Sekolah untuk mengikutsertakan guru dalam kegiatan Gerakan PANDAI.

b. Siswa-siswa dari sekolah tersebut mengikuti Bebras Challenge.

c. Publikasi Artikel Pengabdian Kepada Masyarakat.

3. Foto Kegiatan.

Berikut merupakan Foto Kegiatan Workshop, Roadshow, Latihan dan Lomba Bebras:

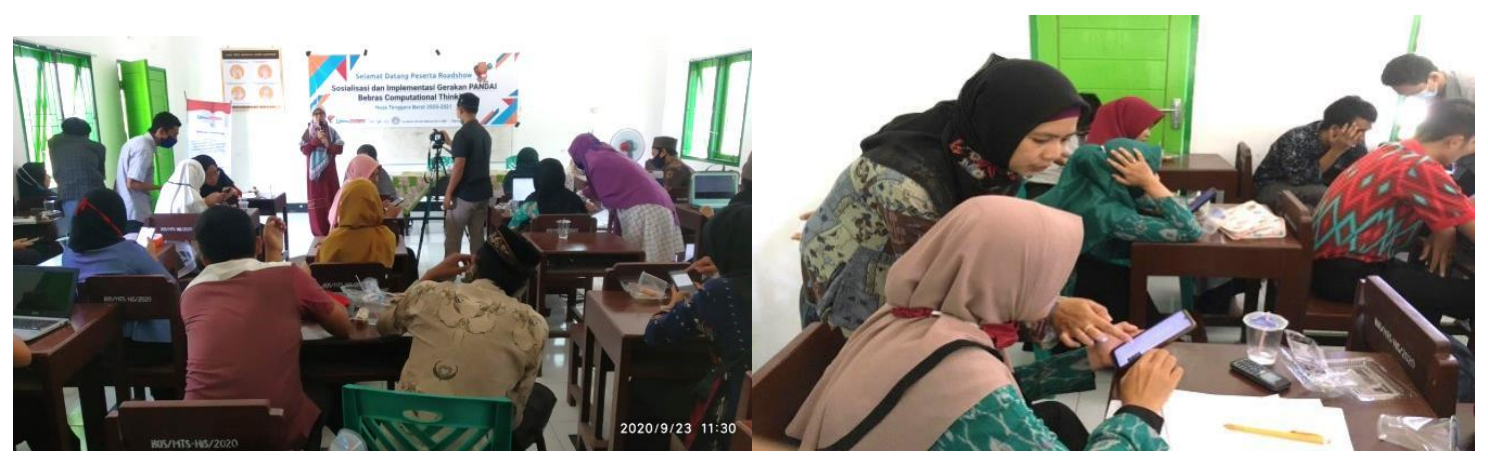

Gambar 1. Kegiatan sosialisasi di Yayasan Nurul Islam Sekarbela Mataram 


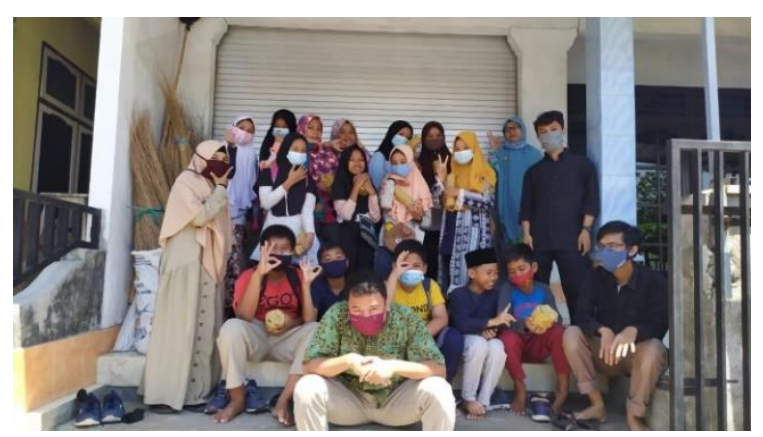

Gambar 2. Foto kegiatan bersama peserta Bebras Challenge dari siswa MI NW Mercapada
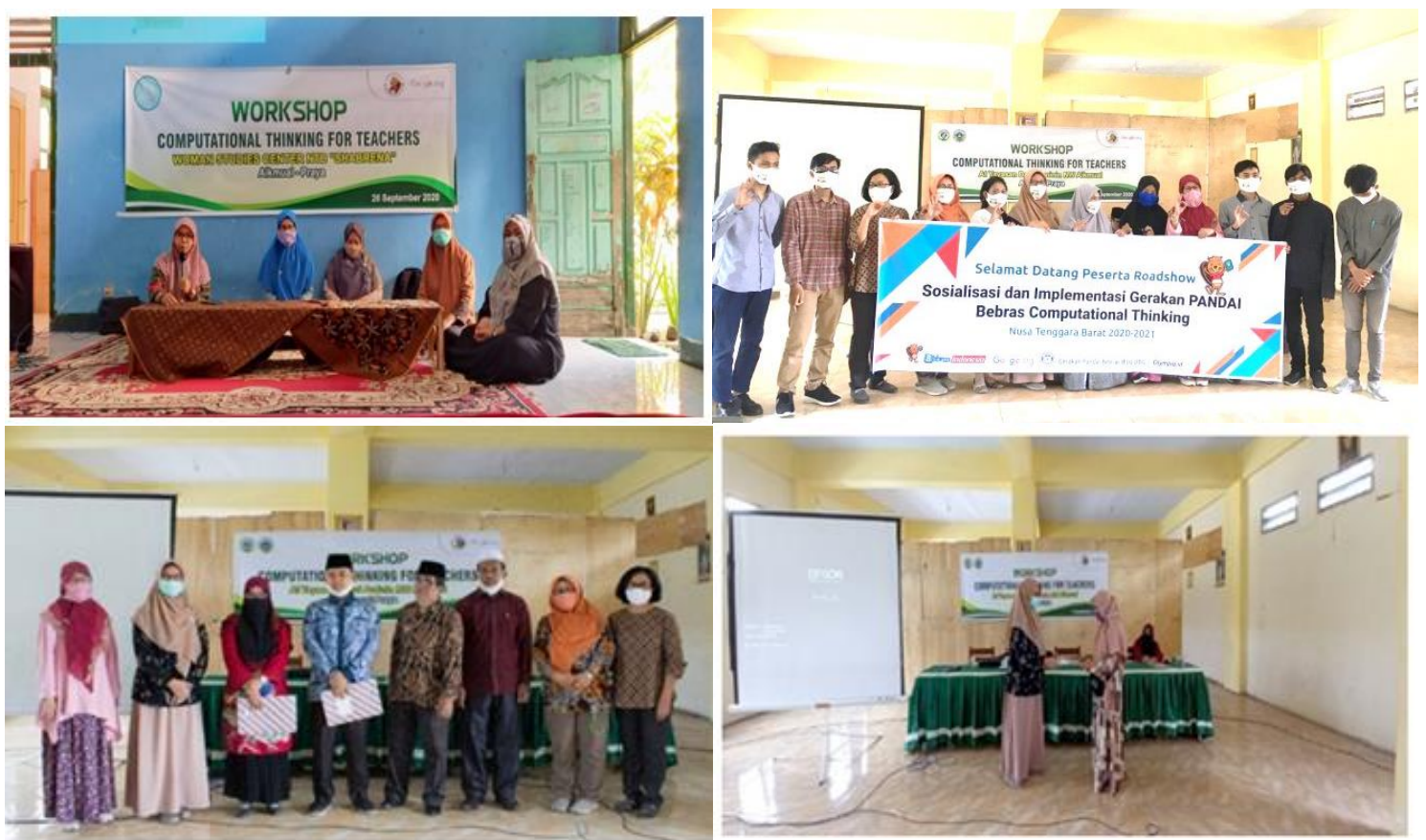

Gambar 3. Foto kegiatan sosialisasi di Madrasah Ibtidaiyah dan Madrasah Tsanawiyah Aikmual Lombok Tengah

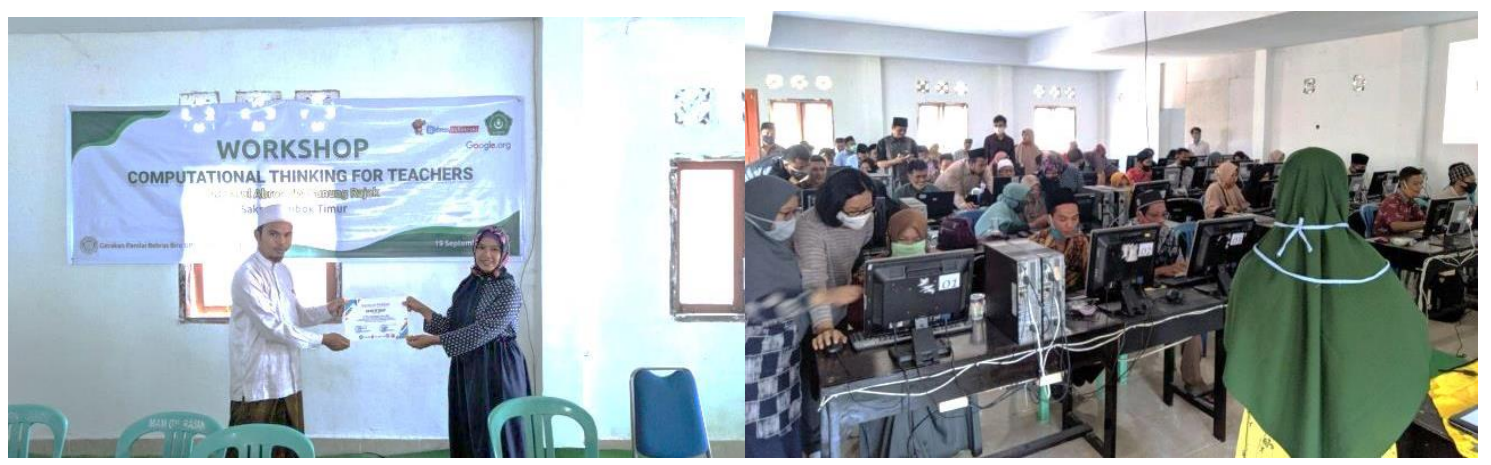




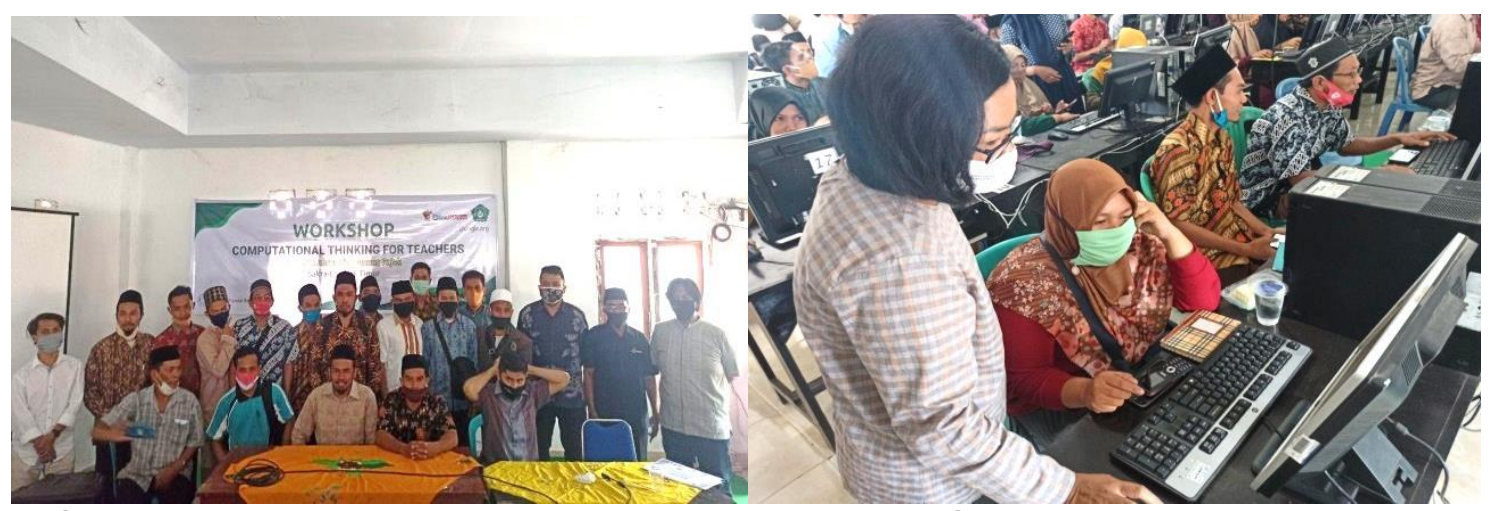

Gambar 4. Foto kegiatan sosialisasi di Yayasan NW Gunung Rajak Lombok Timur

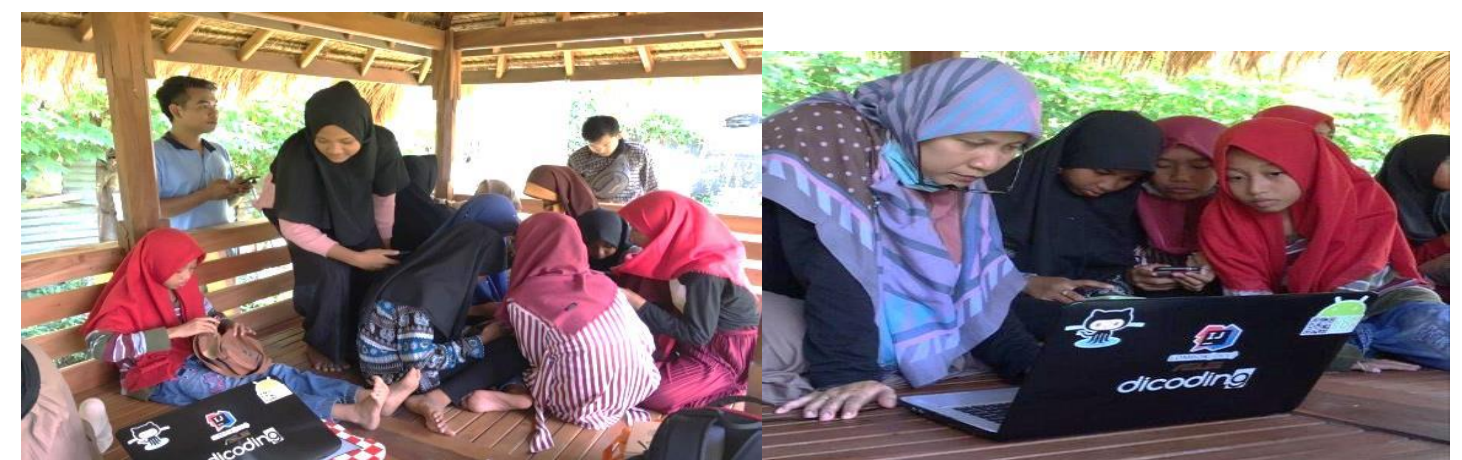

Gambar 5. Foto kegiatan pendampingan peserta Bebras Challenge SDN 2 Jenggala Lombok Utara

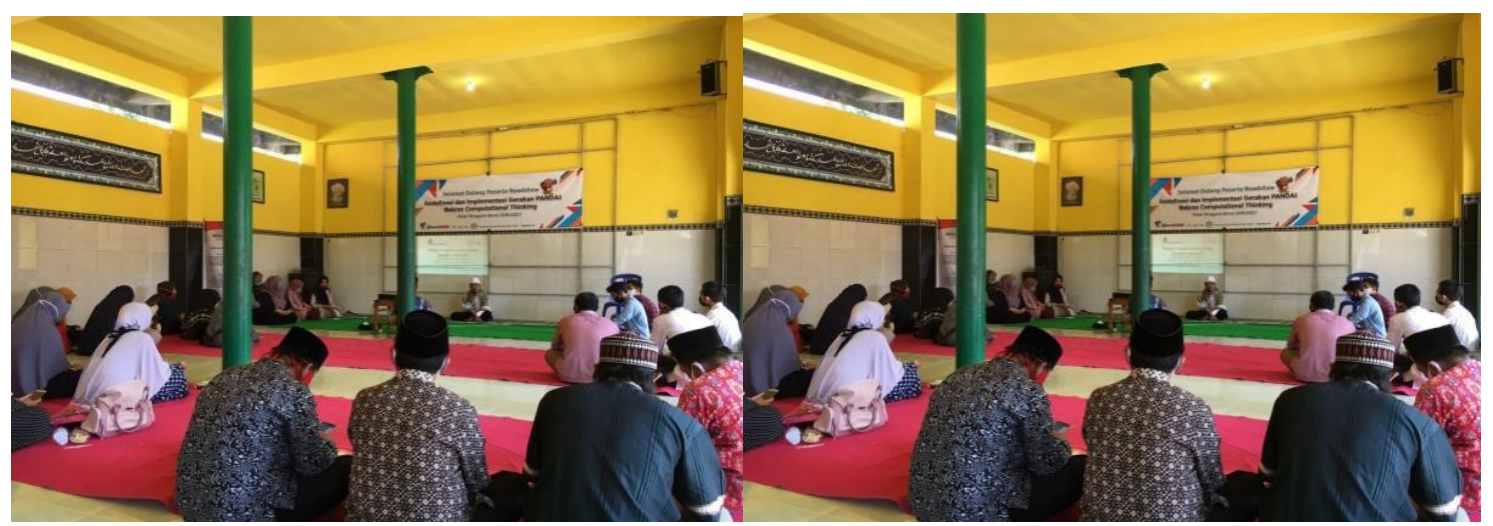

Gambar 6. Foto kegiatan sosialisasi Bebras CT di NW Selaparang Lombok Barat

\section{Status Luaran}

Dalam menghadapi era industri 4.0 semua kegiatan akan selalu berhubungan dengan media digital. Generasi kedepannya diharapkan dapat mampu bersaing dan mengembangkan kemampuan pemahaman terhadap dunia digital dalam hal ini di bidang informatika. Agar memiliki kemampuan tersebut Bebras Biro UBG berusaha untuk memberikan solusi dalam memperkenalan computational thinking Bebras dalam dunia pendidikan melalui sosialisasi ke sekolah - sekolah khususnya beberapa sekolah yang ada di NTB. Kegiatan CT Bebras ini dilaksanakan karena melihat minimnya pemahaman dan kesadaran guru dan siswa terhadap computational thinking.

Hasil status luaran yang diperoleh dari pelatihan dan pendampingan Bebras CT https://journal.universitasbumigora.ac.id/index.php/ADMA 
kepada guru dan siswa di sekolah-sekolah di Lombok NTB ialah bahwa terjadinya peningkatan pengetahuan siswa terhadap CT Bebras serta adanya ketertarikan guru-guru dalam menerapkan CT dalam mata pelajaran Informatika, IPA, Matematika, Bahasa Indonesia, Bahasa Inggris, dan IPS. Dari hasil evaluasi yang dilakukan pada akhir kegiatan dapat diketahui bahwa mitra sasaran (guru) dari daerah Lombok Tengah, Lombok Barat, Lombok Timur dan Mataram memiliki presentase tingkat atau jumlah mata pelajaran bahasa inggris yang di ampuh sebayak 9,5\%, guru matematika sebanyak $28,4 \%$, guru informatika sebanyak 3,4\%, guru IPS sebanyak 14,9\%, guru bahasa indonesia sebanyak $24,3 \%$, dan guru IPA sebanyak 19,6\%. Presentase dapat dilihat pada Gambar 7. Jumlah Mata Pelajaran yang di Ampu.

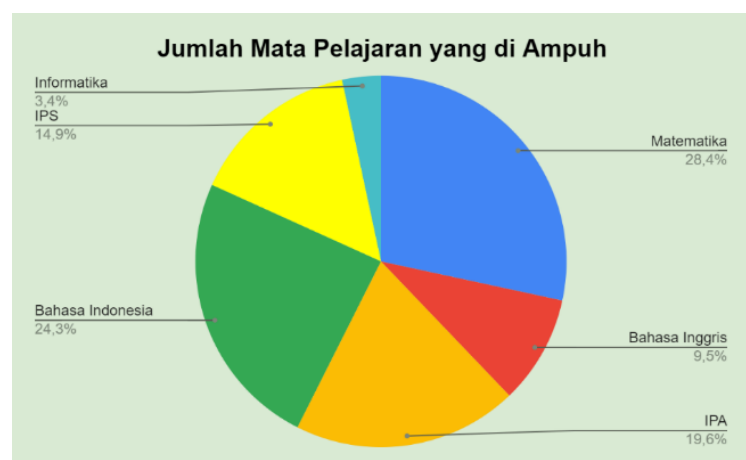

Gambar 7. Jumlah mata pelajaran yang di ampu oleh guru

Sedangkan mitra sasaran dari daerah Lombok Tengah, Lombok Barat, Lombok Timur dan Mataram yang menyatakan bahwa mereka tertarik untuk menerapkan computational thinking yaitu sebanyak $24,7 \%$ guru menyatakan sangat setuju, dan guru yang menyatakan setuju sebanyak $72,2 \%$. Sedangkan $0,6 \%$ guru menyatakan tidak setuju dan sebayak 2,5\% guru netral. Dari hasil tersebut dapat diketahui bahwa sebagian guru/mitra sasaran kegiatan pengabdian masyarakat ini menyatakan tertarik untuk menerapkan computational thinking pada mata pelajaran yang diampunya. Ilustrasi dapat dilihat pada Gambar 8. Tingkat ketertarikan Guru dalam menerapkan Computational Thinking pada Mata Pelajaran.

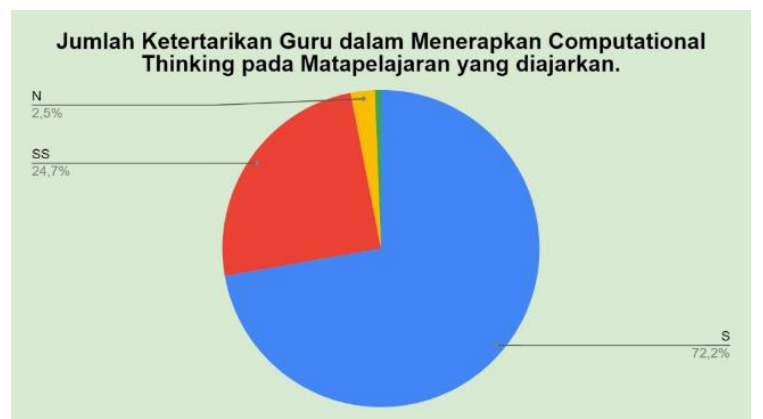

Gambar 8. Tingkat ketertarikan guru dalam menerapkan computational thinking pada mata pelajaran 


\section{Kesimpulan}

Kegiatan pelatihan dan pendampingan computational thinking bebras kepada guru dan siswa yang telah dilaksanakan pada tahun 2020 dalam berbagai bentuk kegiatan seperti roadshow CT Bebras ke sekolah - sekolah dengan mengharapkan tujuan dari kegiatan tersebut dapat tercapai dengan baik. Pelaksanaan kegiatan tersebut di lakukan di beberapa sekolah-sekolah yang ada di Kota Mataram, Lombok Barat, Lombok Tengah, Lombok Utara, dan Lombok Timur yang sudah bergabung menjadi mitra dalam pelatihan dan pendampingan computational thinking bebras 2020. Dalam pelaksanaan kegiatan ini diikuti oleh beberapa dosen dan mahasiswa sebagai volunteer Bebras Biro UBG. Program ini merupakan program kerja pelaksanaan Bebras Biro Universitas Bumigora. Target dari kegiatan ini agar bisa memberikan dampak yang signifikan kepada beberapa pihak yang terlibat khususnya para guru SD/MI, SMP/MTs, SMA/MA. Sehingga pihak yang terlibat juga dapat menerapkan metode pembelajaran computational thinking dalam mencari pemecahan masalah dan mengungkapkan solusinya.

\section{Ucapan Terimakasih}

Terimakasih kepada Kepala LPPM Universitas Bumigora yang telah memberikan izin untuk melakukan PKM. Kepada Bebras Indonesia yang memberikan kepercayaan kepada Dosen untuk menjadi Biro Bebras. Kepada tim relawan sekligus menjadi tim PKM.

\section{Daftar Pustaka}

Ayub, M., \& Karnalim, O. (2017). Edukasi Berpikir Komputasional Melalui Pelatihan Guru dan Tantangan Bebras untuk Siswa di Bandung pada Tahun 2016. 2(2), 12-18. https://doi.org/10.31227/osf.io/gwfv5

Grover, S., \& Pea, R. (2013). Educational Researcher. https://doi.org/10.3102/0013189X12463051

Henderson, P. B., Cortina, T. J., Wing, J. M., \& Hazzan, O. (2007). Computational thinking. SIGCSE 2007: 38th SIGCSE Technical Symposium on Computer Science Education, February 2016, 195-196. https://doi.org/10.1145/1227310.1227378

Toedte, R. J., \& Aydeniz, M. (2006). and Impacts on K-12 Science Education. 